International Research Conference on Civil, Architectural and Environmental Engineering

(IRCCAEE)

Istanbul (Turkey) May. 17-18, 2017

\title{
Urban Safe Haven: Planning and Design`
}

\author{
Tara Azad Rauof ${ }^{1}$, Binaee Yaseen Raof ${ }^{1,2}$ \\ 1Department of Architecture, Faculty of Engineering, Cihan University/Slemani campus, Kurdistan Region of Iraq \\ tara.azad@sulicihan.edu.krd \\ 2 Department of Architecture, Faculty of Engineering, Koya University, Kurdistan Region of Iraq \\ binaee.yaseen@sulicihan.edu.krd \\ binaee.yaseen@koyauniversity.org
}

\begin{abstract}
The Civil wars now raging in many regions of Iraq and Syria are resulting in a partial or total destruction of large cities and a huge loss of human life, mainly civilians. Once the war ends and peace prevails, engineers and other professional people will face a massive task of rebuilding the demolished cities, and then it would be tremendously importance to make a decision about planning and reconstructing them primarily in a way so that minimum casualties will occur if ever a similar conflict happens again. The old towns were not planned for such a kind of war. Safety and protection of facilities in the form of shelters, basements, and tunnels should be taken into considerations in any new town to be built especially for women, children, old and sick people. Secondly, the new master plan should include the new approaches of sustainability. It is possible to lay down certain criteria from the beginning so that the basics are provided in the design for future expansion. Costs of such projects and the time it takes should not become the main obstacles when the safety of civilians and an eye on the future are the prime objectives.

A new theme of an urban division has recently become widely fashionable. The nature and impact of the idea of splitting existing cities such as Johannesburg, Nicosia, Beirut and Jerusalem among other reasons lead us to consider the need to plan larger numbers of medium populated town rather than fewer numbers of huge cities.Economical and commercial reasons usually influence planning decisions; some objections to such project are expected but if such protections save many civilian lives then why not build a town with more humanitarian needs, one which can be called safe haven.
\end{abstract}

Keywords: post-war reconstruction, Safety, Redevelopment, Urban Planning, Resources, Sustainable development Renewable energy

\section{Introductions}

Natural disasters or man-made disasters eventually lead to the same heart breaking images of wasted human lives, populations forced to flee and cities laying in ruins. The only difference between them is that Natural disaster have a clear ending while the man- made is unpredictable and can last for decades. That's why we should all agree to set the starting points now "There is an increasing demand to start looking at the day after," said Raja Rehan Arshad, the WBG's Lead Disaster Risk Management Specialist. "The time is ripe, we cannot stand by until the last embers of the war have died down" said Hilmar von Lojewski, an urban planner who spent most of his life working in the local administration in Aleppo.

According to the Syria Information and Research Initiative (SIRI) at the World Bank Group (WBG) Syria today is a physically shattered and broken nation with estimated economic damages in the six of the biggest Syria's cities [Aleppo, Dar'a, Hama, Homs, Idlib, and Latakia] Chart. 1, are US\$7billion and at least 280,000 dead. Reconstruction could take between fifteen to twenty years to complete. 


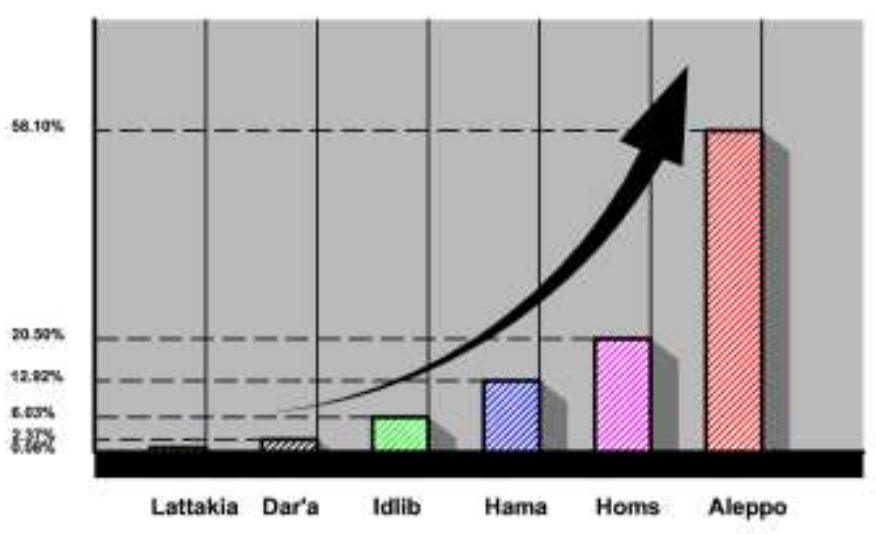

Chart. 1: "Total Damages per city"

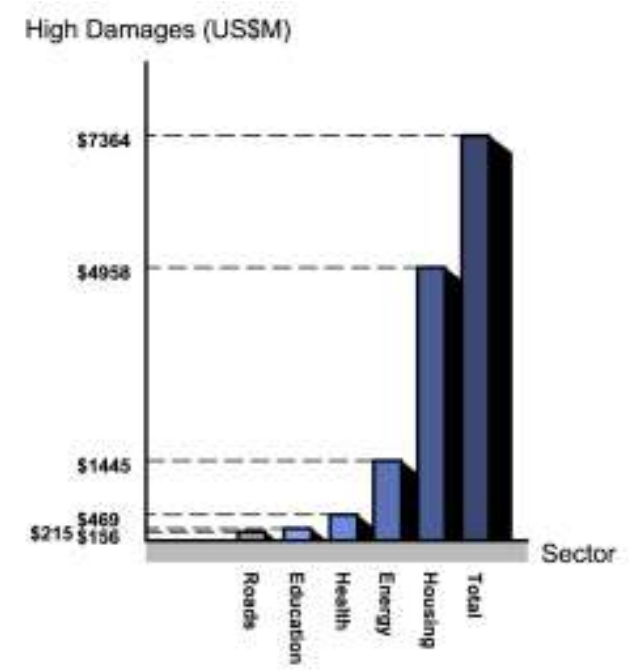

Chart. 2: "Damages per Sector"

If we take Aleppo the world's oldest ancient, cosmopolitan city as an example: at least 24,000 civilians have died and 1.25 million inhabitants are forcibly displaced. $80 \%$ of the buildings have been destroyed, among 100 mosques; a quarter is reduced to rubble while the rest are badly harmed [1]. If a qualified team of engineers, architects, landscape designers and archaeologists don't start with a reconstruction plan immediately, the world will have to pay for it in a long term. Otherwise, when the peace prevails, international investors and others will reconstruct in a rapid and uncoordinated manner that will guarantee the loss of both historical glory and futuristic development of Aleppo permanently.

\section{Reconstruction Process}

\subsection{The Absence of Planning}

The dream of rebuilding those demolished cities usually start with a master plan that covers reconstruction and urban development with a strategic thinking, consultation with the local stakeholders and professionals, setting a priority list and last but not least demanding foundation for the future expansion. Considering the sustainable principle in the redesigning process, many lessons to be learned from post war reconstructed regions in the past such as Germany, Beirut, and Bosnia. Those cities will be more aggressively changed than by the war itself in the absence of an overall plan for reconstruction.

Prioritizing the repair and reconstruction projects by means of urgency is the key to success, starting with identifying infrastructures which had suffered light, medium or heavy damages, electricity networks and water supply systems are the nerve of life of any city. Rehabilitation and resettlement in the form of apartment blocks or individual residential houses should come at the second place which is also have been a priority for both local inhabitants and the international community, then followed by Road network, bridges, Schools, hospitals and other facilities.

The absence of an implementable planning at any stage in the process of demolition, repair, and reconstruction can lead to vital damages. Many vital changes can be made to the regulation plans such as selling off public land to private investors, issuing variable kind of permissions without any reference to the central municipality or the local stakeholders, allowing land use changes, for example, replacing green areas with construction lands and messing up property cadastre in order to cover illegal occupation and construction that have a negative impact on the environment.It is possible for such towns to be rebuilt in phases but it is utmost important to have a master plan with the proposed location of these facilities in it. After the Second World War, a plan called the Marshal plan was implemented for the rebuilding of a decimated Europe. Having such a plan for Syria and Iraq will simulate the start point of reconstruction, the international economic contribution and a powerful international commitment to the reconstruction. A rough estimation for Syria reconstruction plan are hundreds of billions of dollars [2]. 


\subsection{Safe Haven:}

The tremendous high number of civilian casualties as mentioned before is mainly because of the raging war but on the other hands, the lack of protection; safe shelters and poor medical services can be responsible too for a large waste of human lives. We believe that precaution is better than cure, it is better to take action in advance by preparing these new cities so that if ever a similar conflict happens again minimum casualties will occur. The old towns were not planned for such a kind of war, women, children, old and sick people are the victims how mostly suffer at the time of wars. Our ancestors have taken safety and protection very seriously, that is why the Great Wall of China or many medieval castles and fortresses were built and even London underground was allocated for civilians during the world wars. Nowadays there is no limit to what technology and engineering can achieve and to rebuild the needed facilities underground in the early stages would be more feasible than doing them after the population is back. It is also possible to design other essential structures for protection such as shelters, undergrounds, and tunnels to be incorporated in the master plan. For instance Hospitals with proper basement shelters and bunkers supplied by all the necessary emergency departments. Archives with undergrounds storages where regulation and cadaster are saved. Museums containing ancient and archaeological pieces survived thousands of years should be able to survive this war too. Schools to be built in each district having two stories or more to provide the necessary facilities for two or more schools on the same grounds with basement for shelters.

\subsection{SPLIT IDEA/ Urban Division}

The reasons that brought us to this part are two, the first one is that nowadays there are large scales of relocations and resettlement of refugees and these are expected to continue even after the end of hostilities, therefore, it would be necessary to consider the sizes and numbers of these new towns. It is more feasible to go for large numbers of towns with medium population than a small number of town with a large number of population. As it seen in these urban fighting, civilian casualties are much higher in large cities than in small towns, in large cities, it is more difficult for civilians to escape an internal fighting between different districts within the same city. More damages and casualties occur on densely populated large cities with its high rise buildings, comprehensive and intricate infrastructures than in small towns. The construction could be done in phases, priority should be given to the infrastructure, hospital, schools. etc. The start point should be while the displaced people are still living in the surrounding camps.

The second reason is the fact that urban division or splitting large cities such as Johannesburg, Nicosia, Beirut \& Jerusalem has recently become widely fashionable. Urban planners could play a more significant and a more positive role in designing /planning the new medium populated town and the renovation of old city centers.

Linear planning or sequence planning which one can be more achievable? According to us, sequence planning has more chance of success because each sequence can independently reach an acceptable level of success regardless of the success of an adjacent sequence. Each one can individually reach success or fail.

\subsection{Promoting Sustainable Principles in Reconstruction Process:}

In a reconstruction process for Syria and Iraq it is important to consider sustainable principles as sustainable cities have become key features of the landscape of environmental governance. Achieving a decent standard of living for present and future generation using natural system, this is a general concept of sustainable development with creating a link between local social, economic and ecological system to global concerns [7]. In this paper, it will be shown how sustainable development extends the positive attributes and offers a multigenerational vision of community building.

This vision integrates multiple societal values and enhances local imagination, understanding, and commitment to defining solutions for the common good.

\subsection{Principle of Sustainable Development:}

\subsubsection{Harmony with Nature}

Land use and development activities should continue with the essential cycle and life support functions of ecosystems as a complete system. Protecting essential ecosystem and improving sustainable resource development are crucial principles. 


\subsubsection{Livable Built Environment}

Physical space adapted to desire activities of inhabitants is appositive choice for making connection between location, shape, density, mix, proportion and quality of development and people with urban form.

\subsubsection{Place Based Economy}

A local economy should attempt to operate within natural system and natural resource base, which is important for future economic development. Therefore, processes of nature should be used up on more quickly than nature can renew them.

\subsubsection{Equity}

Improving the conditions of low -income populations should be recognized in urban patterns with eradicating poverty by equal access to social and economic resource.

\subsubsection{Polluters Pay}

Bearing the cost of pollution and other harms by polluters.It is important to incorporate goals for climate protection and policy implementation this visions in developing cities in general and other parts of it such as transportation planning.In spite of the fact that conceptualization and examining sustainable issues are important but during redeveloping these cities taking consideration of the obstacles that have overcame are important too, such as the conflicts over urban sustainability and the consequent implications for sustainability.

\subsection{An Example of sustainable (Zero Carbon city)}

Masdar city by Foster and Partners Abu Dhabi, United Arab Emirates: Set to house 50,000 people. Masdar's design represents a specific response to its location and climate. Sustainable plan is a successful example for showing the rapid urbanization of the cities and energy reduction.

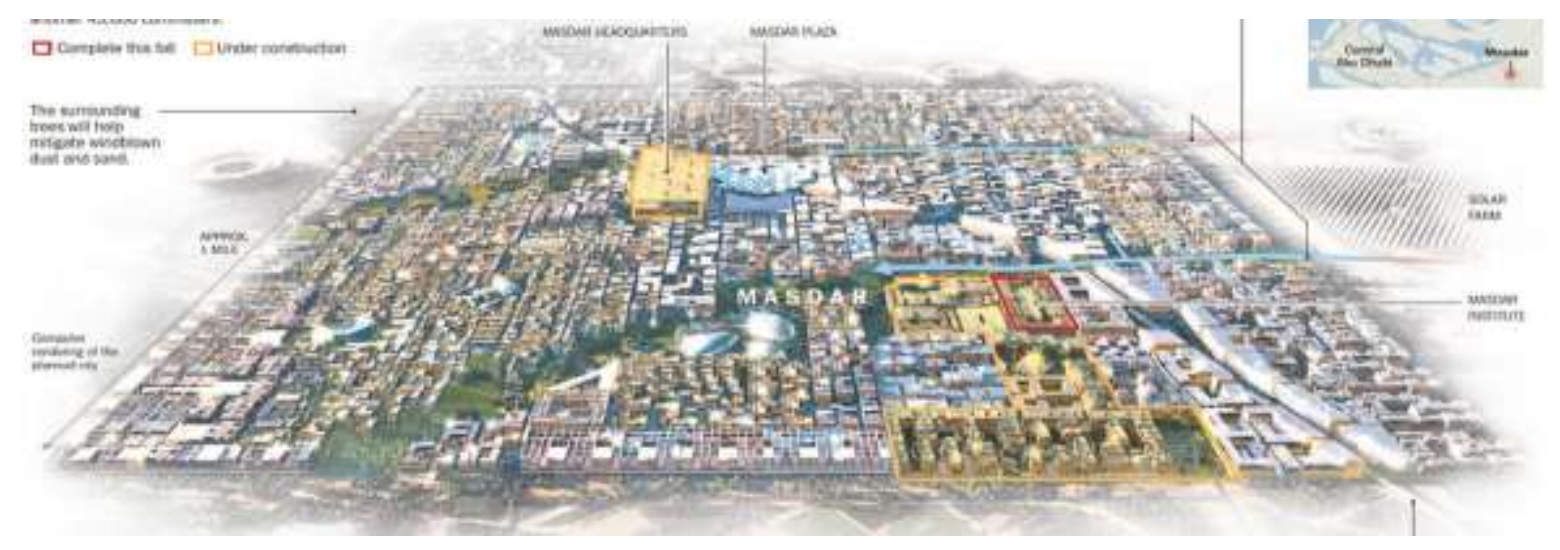

Fig.1. Shows the top view of the new design of Masdar city [11]

Masdar City combines state-of-the-art technologies with the planning principals of traditional Arab settlements to create a desert community that aims to be carbon neutral and zero waste such as :

- Captures prevailing winds is naturally cooler and more comfortable during the high summer temperatures.

- Rooftop solar technology and one of the largest photovoltaic installations in the Middle East for generating clean energy

- The city itself will be the first modern community in the world to operate without fossil-fueled vehicles at street level. 
- The city is designed to encourage walking, while its shaded streets and courtyards offer an attractive pedestrian environment, sheltered from climatic extremes since the programmable cars can move inside the city.

- The land surrounding the city will contain wind and photovoltaic farms.

\subsection{Sustainability is achieved in the Design of the City by Studying the Following}

Site and Climate: The city grid is angled to minimize solar penetration of the streetscape. It also helps capture and funnel prevailing winds.

Form and Massing: The orientation of the buildings was designed to optimize street shading and provide overshadowing to adjacent buildings. Insulated facades to all buildings within the masterplan and balconies with solar screens in residential blocks.

Renewable Energy: A rooftop PV array helps provide the electricity requirements of the buildings whilst shading the roof to limit solar heat gains. A near site 50MW PV array and concentrated solar power plant help provide the energy requirements of Masdar.

Mobility and Connectivity: The city was designed for a healthy lifestyle by encouraging walking, through improving the microclimate and the positioning of lifts to encourage stair use

Land and Ecology: Landscaping and ecology were used intelligently across the streetscape to provide both shade and cooling through the natural process of evapotranspiration

Wellbeing: The design has an enhanced microclimate through shade, material selection for thermal mass, wind movement and evaporative cooling from water features and the wind tower

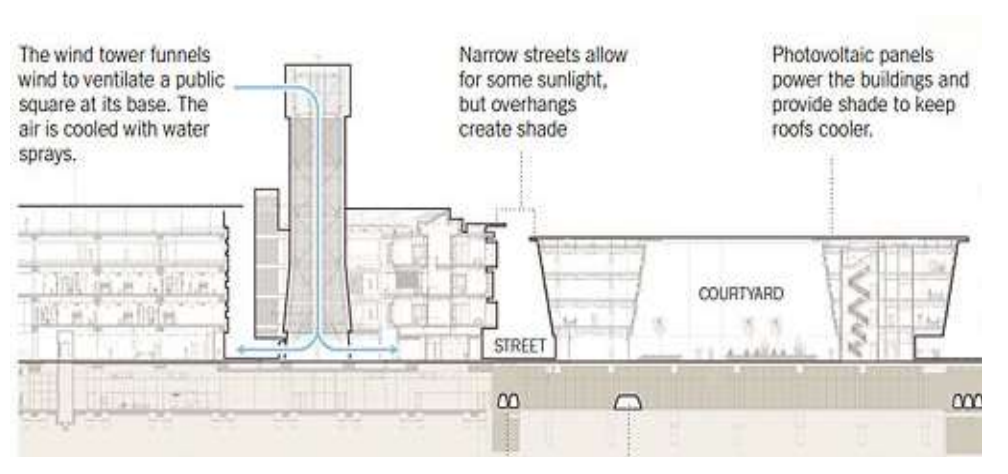

Fig.2.The wind tower, Narrow Streets and Phoyovoltaic Panels [11]

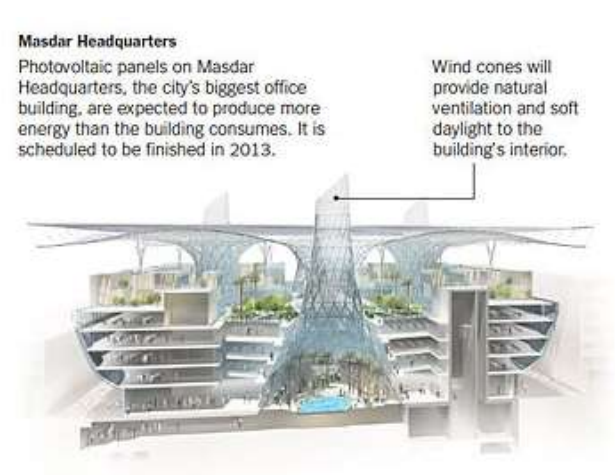

Fig3.Masdar Headqurters produce more energy than the building need,[11]

\section{Conclusion}

This paper attempt to show some alternative solution for rebuilding the demolished cities and some projects for saving many civilian lives by building a town with more humanitarian needs, one which can be called safe haven. Explaining a significant role in designing the new medium populated town and the renovation of old city centers and giving the priority to the infrastructure.

Trying to concentrate on the sequence planning because each sequence can independently reach an acceptable level of success. Encouraging Sustainable development to conserve and enhance the resource base, by gradually changing the ways in which these cities will be designed. Moreover, Nations must be allowed to meet their basic needs of employment, food, energy, water and sanitation.

\section{Recommendation}

1. Start point of response and emphasize a master plan for reconstruction should be much prior to the end of the war.

2. Preparing a well-organized plan that goes from specific to general according to priority will prevent vital damages. 
3. Bringing old strategies of urban design to life by introducing them to the world in modern form can save us futuristic casualties.

4. Reinforce the newly reconstructed cities with means of protection will allow self-defense and prevent them from being exposed to many hazards.

5. Population density is the biggest obstacle in a condition of evacuation, protection, accessibility and international intervention.

6. Focusing on modern themes that rose from reality and others experiences in recent years. splitting versus unifying.

7. considering the principle of sustainable development to achieve the balance between economic, environmental and social needs, allowing prosperity for now and future generations by avoiding the over consumption of key natural resources.

\section{References}

[1] The World Bank. (May 24, 2016). The Importance of Planning Syria's Eventual Reconstruction. Available: http://www.worldbank.org/en/news/feature/2016/05/24/the-importance-of-planning-syria-s-eventual-reconstruction .

[2] The World Bank. (April 2016). MENA Economic Monitor, April 2016: Reconstruction for Peace in Syria. Available:http://www.worldbank.org/en/region/mena/publication/mena-economic-monitor-april-2016-reconstructionfor-peace-in-syria .

[3] BALADI. (May 2016). Syria's ruined cities will need decades to recover from war. Available: http://baladinews.com/en/news/details/6592/Syria\%E2\%80\%99s_ruined_cities_will_need_decades_to_recover_from_war .

[4] Jelena Mitrovic, "Bridging the divides- 'Unifications' of Mostar," M.S. thesis, Nationalism studies Programs, Central European University, Budapest, Hungary, 2008.

[5] Shipra narang Suri, "URBAN PLANNING AND POST-WAR RECONSTRUCTION UNDER TRANSITIONAL ADMINISTRATIONS: THE CASE OF MOSTAR,” Ph.D. thesis, 2009.

[6] Craig Larkin, "Reconstructing and Deconstructing Beirut: Space, Memory and Lebanese Youth," M.S. thesis, Department of Politics, University of Exeter, 2009.

[7] Philip R.Berke, Maria Manta Controy (Januray 2000) “Are We Planning for Sustainable Development? An evaluation of 30 Comprebensive, Journal of the American Planning Association . [online]. 66(1).pp21-33

[ https://www.researchgate.net/publication/235357584_Are_we_planning_for_sustainable_development_An_evaluatio n_of_30_comprehensive_plans ]

[8] Harriet Bulkeley, Michele Betsill (September 2005) "Rethinking Sustainable Cities: Multilevel Governance and the 'Urban' Politics of Climate Change" Environmental Politics[online], 14(1), pp (42-63) http://www.tandfonline.com/doi/pdf/10.1080/0964401042000310178

[9] Jeffrey R Kenworthy . (April 2006) "The eco-city: ten key transport and planning dimensions for sustainable city development". [online],18(1), pp (67-85). http://journals.sagepub.com/doi/pdf/10.1177/0956247806063947

[10] Jenks M. and Dempsey N.Future forms and design for sustainable cities $1^{\text {st }}$ ed. New York, USA 2005, Ch 3 , pp 285371

[11] Foster and Partner (2007) "Masdar Development Abu Dhabi , United Arab Emirates" [online] Available http://www.fosterandpartners.com/projects/masdar-institute/ 